\title{
Methodological application of Location of service Public Bike. Service MUyBICI of Murcia
}

\author{
Roberto José Liñán Ruiz \\ Departamento Ingeniería Civil, Universidad Católica de Murcia (UCAM) \\ Fernando J. Berenguer Sempere \\ Departamento Ingeniería Civil, Universidad Católica de Murcia (UCAM) \\ José Antonio Vera López \\ Universidad de Málaga \\ Ana Belén Pabón Dueñas \\ Universidad de Málaga \\ Salvador Merino Córdoba \\ Universidad de Málaga
}

\begin{abstract}
The use of non-motorized means of transport such as the bicycle, brings many benefits to the user and for the city in terms of costs and health for the first and decreased environmental pollution for the city.
\end{abstract}

To find the optimal location for placement of the different parties to public bike, aims to attract the usual user and potential, have the feasibility of switching modes without any restrictions, while generating the ability to balance the demands users towards sustainable modes of transport, with special attention to cycling and public bike loan.

The implementation of this methodology is performed in the municipality of Murcia (Spain) due to the opening of its public bicycle system MUyBICI which will have 60 benches, with a total of 1,200 posts anchor and put into circulation 600 public bicycles.

As selection criteria to be considered for the optimal location of the beds, the existing network of bike paths were considered, roads used by all users of the public highway, a description of travel and a database information with different land uses and socioeconomic data transport areas.

In this paper an analysis model and application for optimal design of banking locations for Murcia MUyBICI service occurs. Specifically, they define what are the best locations to attract a larger number of users, in order to achieve a change in the percentage of the modal split of the municipality, increasing the number of users MUyBICI service.

This work comes under the direction of the Bicycle Office of Murcia, part of the ALEM (Local Agency for Energy and Environment) service under the Department of Environment of the City of Murcia. 


\section{INTRODUCTION.}

Given the different areas of study related to cycling mobility, some of the work and scientific studies have been carried out, related to systems of public bicycle and its features for planning, design and management of these systems are exposed.

The appearance of the public bike systems has allowed supply and facilitate access to a segment of the population that otherwise would not have access to the bicycle as a mode of habitual or rerouting. In recent years there have been various projects that promote the inclusion of public bicycle as an active part of the city, some examples of European cities that have launched this initiative as Barcelona, Berlin, Paris, London, Seville, etc. This type of service systems provide practical, fast and designed for everyday use of commuting mobility, as it is a mode of transportation with greater flexibility in urban journeys than other modes of transport. It is considered a public bicycle as another mode of public transport.

The evolution of public bicycle systems is classified into three types or generations: the first, started in Amsterdam in 1965, consisted of a free system of bicycles. The second type or generation, was based on a public rental system that started in Copenhagen in 1995. This form of loan was quite similar to that commonly used in supermarkets and shopping malls for loan shopping cart. The difficulty of this system was at a low rental price and the nonexistence of a user registration and tracking bicycles. Finally, the third generation type of loan bikes are based on information systems of technology emerged in Rennes in 1998 (Demaio 2009).

Finally, a fourth generation (Bea 2009) is proposed. the integration of public bike with the rest of the public transport offer an automatic system implemented at points of automated loans managed by a telematic system, from smart cards or integrated transport fertilizers is achieved. This loan system was generalized by different countries in Europe from 2001, with the reference city of Lyon.

The latter case is presented in the city of Murcia by the public bicycle service MUyBICI, which consists of a fully automatic system comprised making positions and deposit and own bicycles.

In relation to the location of the bicycle loan points, stands out as the distance between the parking and bicycle travel destination is an influential factor (Hossain 2003). The same applies to the type of trip taken and security for each user, where the usefulness of bicycle increases with safe parking facility (Replogle 1993).

In the same vein, in the work presented by Bosque and Moreno (2004), concern for finding 
optimal locations using tools geographic information stands. There are different tools optimal location of services that can help locate public bicycle stations depending on the distribution of land use and travel demand.

The public bicycle system of Murcia (MUyBICI) aims to become a way of efficient transport in the city, contributing to displacement healthier. In order to reduce the use of private vehicles, the city of Murcia launched in April 2015 and is currently being implemented. In the first phase will consist of 60 stations or caucuses, with a total of 600 bicycles spread throughout the urban area of the city.

\section{ADOPTED METHODOLOGY.}

The mechanisms for gathering information for the characterization and assessment of cycling mobility, for the municipality of Murcia, differ depending on the different objectives of the study (analysis of service or quality of supply indicators of the current situation, surveys mobility, etc.).

It is intended to achieve optimal spatial location, associated with the minimization of total displacement of users and increased spatial accessibility of potential users to the locations of public bicycle parking. Within the population coverage possible from ensuring a greater number of users with minimum distances to base parking to bicycle.

For the development of research, it has been taken into account cartographic and statistical information from the IGN (National Geographic Institute) and INE (National Statistics Institute). In addition, it has received data from the Survey of Mobility of the Municipality of Murcia (elaborated by GTM1).

First, and on the basis of data in GIS, the potential demand was analyzed at different points of the study area. You need to know the origin of the trip generation and places that produce the attraction of these trips (activity centers). To do this, we have used Census data for 2011, provided from the INE.

For proper placement of the localization, are needed demand data so travel by bicycle. Due to the lack of existing data in the city of Murcia related to cycling mobility, did a distribution by age range of the population to obtain a better measure of the ease of use the bike after implantation service public bicycle MUyBICI.

Similarly, the indicator of demand for the sake of each of the displacement is calculated. This indicator is based on data taken from the Mobility Study of the Municipality of Murcia

1 Transport and Mobility Group at the Catholic University San Antonio of Murcia. 
(2015), where revealed preferences of travel of different users.

To obtain areas with greater attraction in the number of trips, are identified from the data from the Survey of Mobility and availability of different public equipment for each of the census tracts of the study area. To have a more precise analysis of future demand produced by localization of MUyBICI, did obtain the areas with the highest number of trips attracted.

\section{APPLICATION AND RESULTS.}

The effectiveness of the study is based on the appropriate location of parking of the public bicycle in the vicinity of the centers of attraction and trip generation. To this end, the tools used models optimal location within the toolkit Network Analysis Software ArcGIS 10.1.

To start the placement process the 60 parking of MUyBICI, they have needed layers in ArcGIS information on land use, public equipment and socioeconomic data of the population in the study area.

With regard to floor use data, they have been classified by importance the different floor uses, achieving greater relevance residential and industrial and educational facilities. Similar to this classification, the classifications of the different facilities have been given a priority to obligated travel, ie, equipment related to different educativitos centers and business centers.

For data related about population and socio-economic of all census tracts that make up the study area (the historic center of Murcia) different profiles of potential users who might be attracted to the modal shift towards public bicycle is designed. The estimated age range of users aged centered between 16 and 50 years, focuses where a higher percentage of students and workers, these users being those who are more likely to use public bicycle service MUyBICI.

After combining the results of the variables studied, a distribution of the areas of greatest interest to the location of the total of 60 parking for public bicycle that will form part of the service MUyBICI presented. Is observed as areas of the historic center of the city and the corridor that runs to the north of the city are pillars necessary to improve sustainable mobility. The southern area of the city known for its high population density and type of user with great capacity for change of modal split towards cycling transport. 


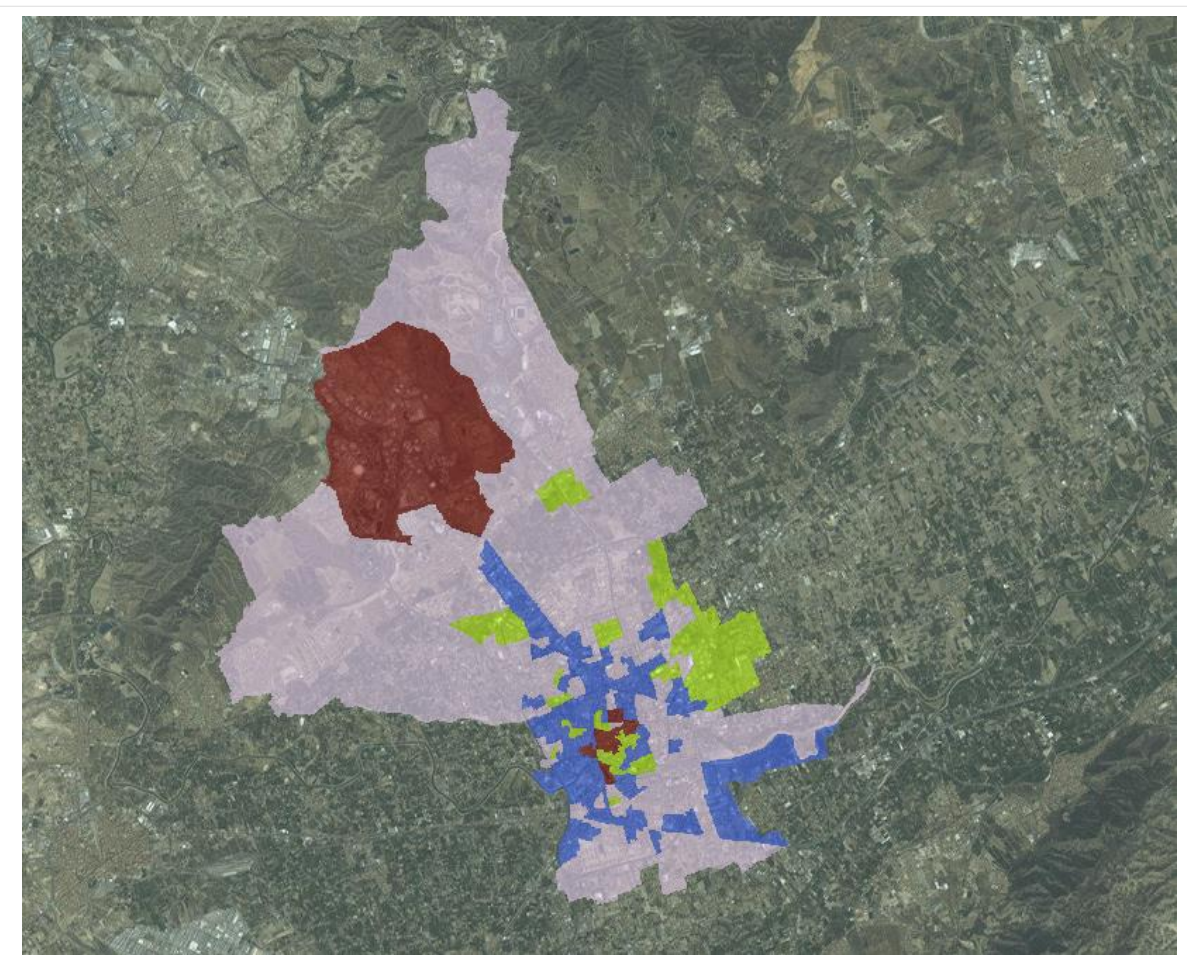

\section{Figure 1 - Distribution of the areas of greatest interest}

Once known areas of greatest interest to the locations of public bicycle stations about from the data in the database of the municipality of Murcia, the locations of the 60 parking that form part of the proposed system. To understand the possibilities of each of the stations, areas of influence that would each of the stops, related to the optimal location of the data from the previous analysis. In this sense it can be seen in the following figure 2, available for different users with respect to a catchment area of 100, 200 and 400 meters respectively.

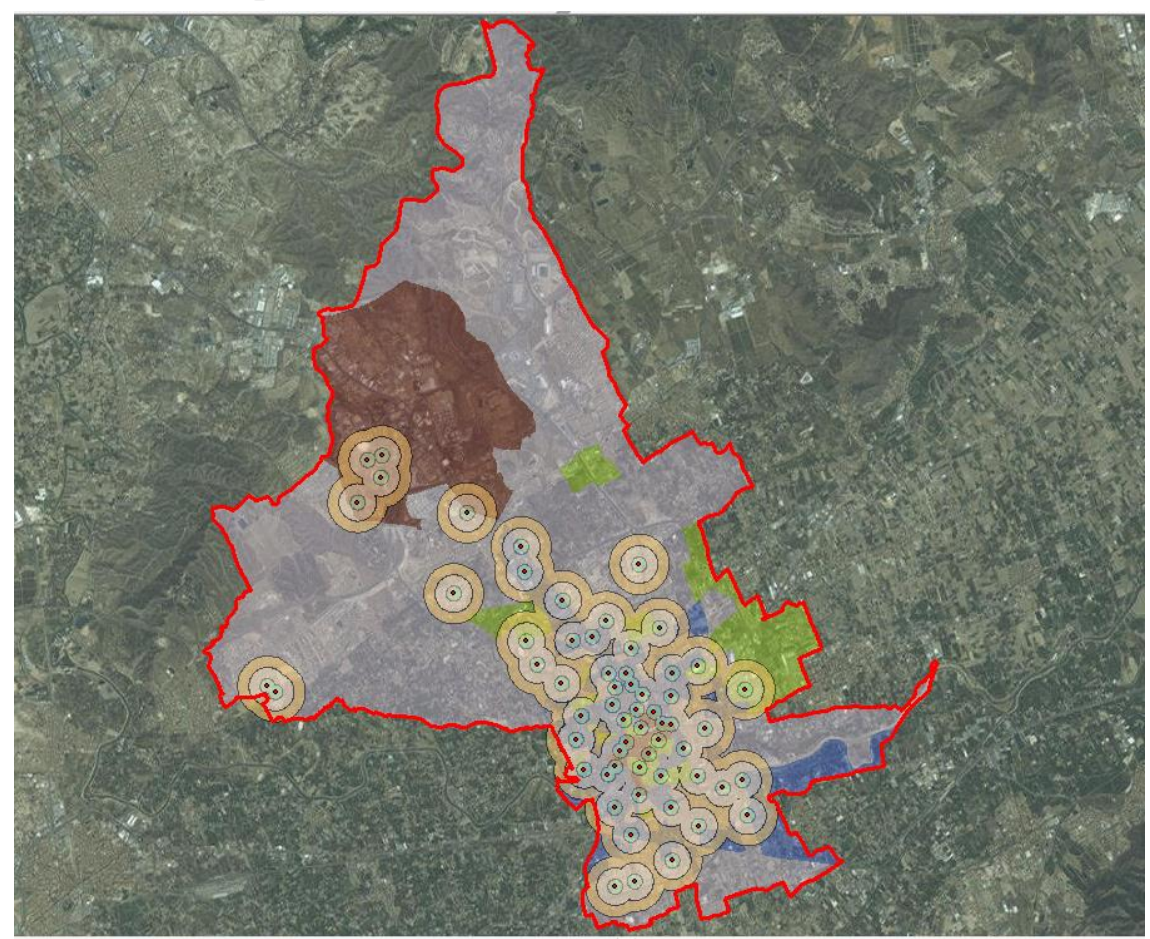




\section{Figure 2 - Catchment area the locations of the parking}

From the tools ArcGIS Network Analyst provides, we analyzed the impedance of the 60 locations of public bicycle system of Murcia. For a better analysis of the results it has taken into account the road network in the municipality of Murcia with the corresponding characteristics of speed and capacity of each of the vials. The impedance between total locations of public bicycle and urban fabric, for a ratio of distances between 100, 250 and 400 meters travel distance from each of the 60 stations analyzed (figure 3 ).



Figure 3 - Impedance of the 60 locations of public bicycle system of Murcia

After the implementation of public bicycle of Murcia (MUyBICI) in April 2015, the bicycle rental system has reached more than 6,700 users with a total of more than 325,000 loans. Of total users, $53 \%$ are women, while $47 \%$ of users were men. By age range, users are aged between 16 and 30 years is $46 \%$, with $42 \%$ of users aged between 31 and 50 years, ending with $12 \%$ of users aged 51 years.

As for the frequency of use of public bicycles, $33 \%$ of users use daily or several days a week system MUyBICI, which implies a level of satisfaction pretty good service, strengthening more and more cyclists users thereby increasing the modal share of cycling to Murcia. 


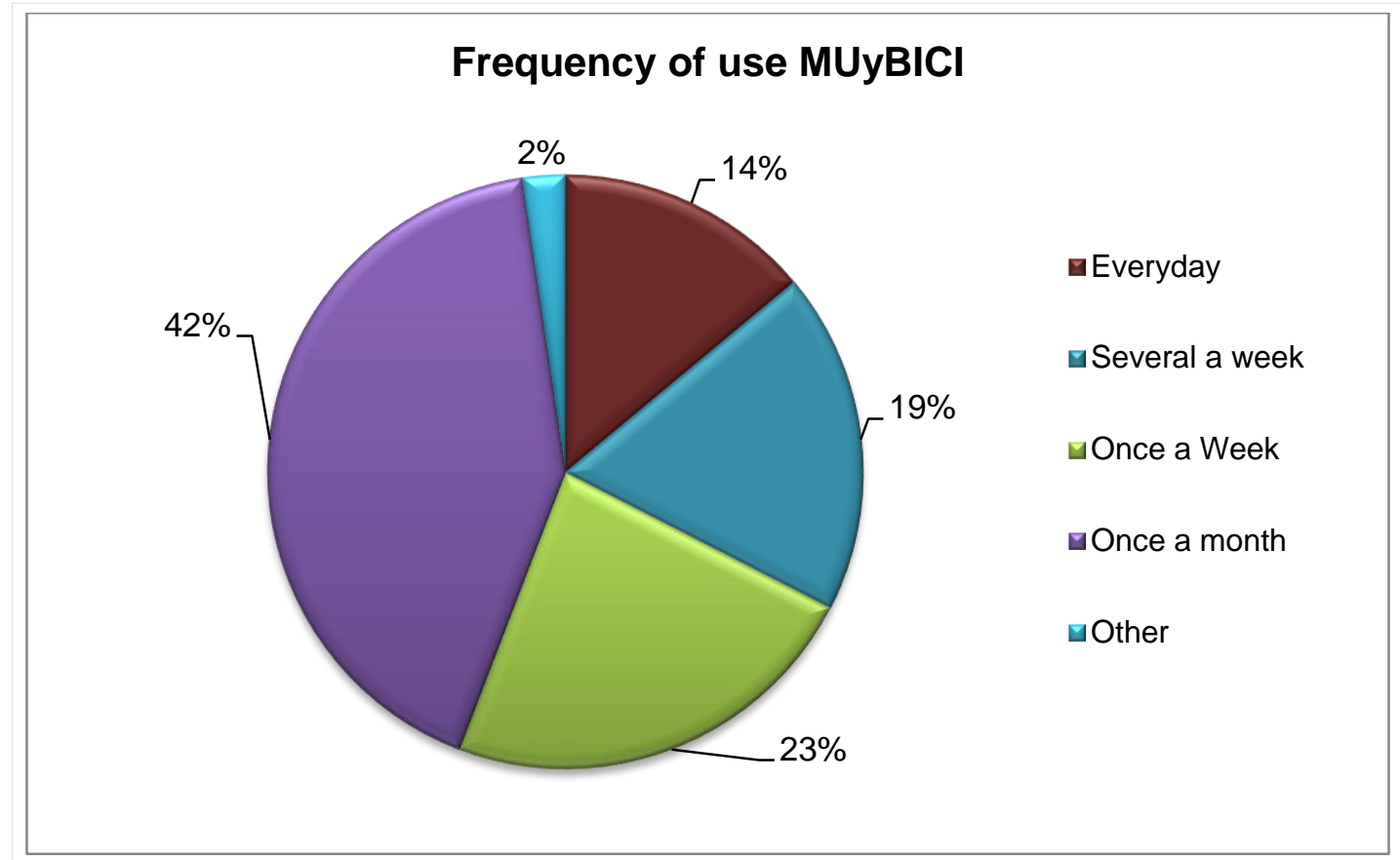

Table 1 - Frequency of use of public bicycle system of Murcia

To analyze the results service MUyBICI, is necessary to expose on stated preferences on public bicycle system of the municipality of Murcia for the different users. The score is established in five categories, from 1 to 5, from worst to best score for each of the questions. Two results are stand out, Mobility Study of Murcia (2015). The first is based on the overall score service MUyBICI, $81 \%$ of citizens give a good rating to the new implementation of mobility of the City of Murcia, highlighting the great reception given among different users, becoming, thus a benchmark for sustainable mobility in the Region of Murcia.

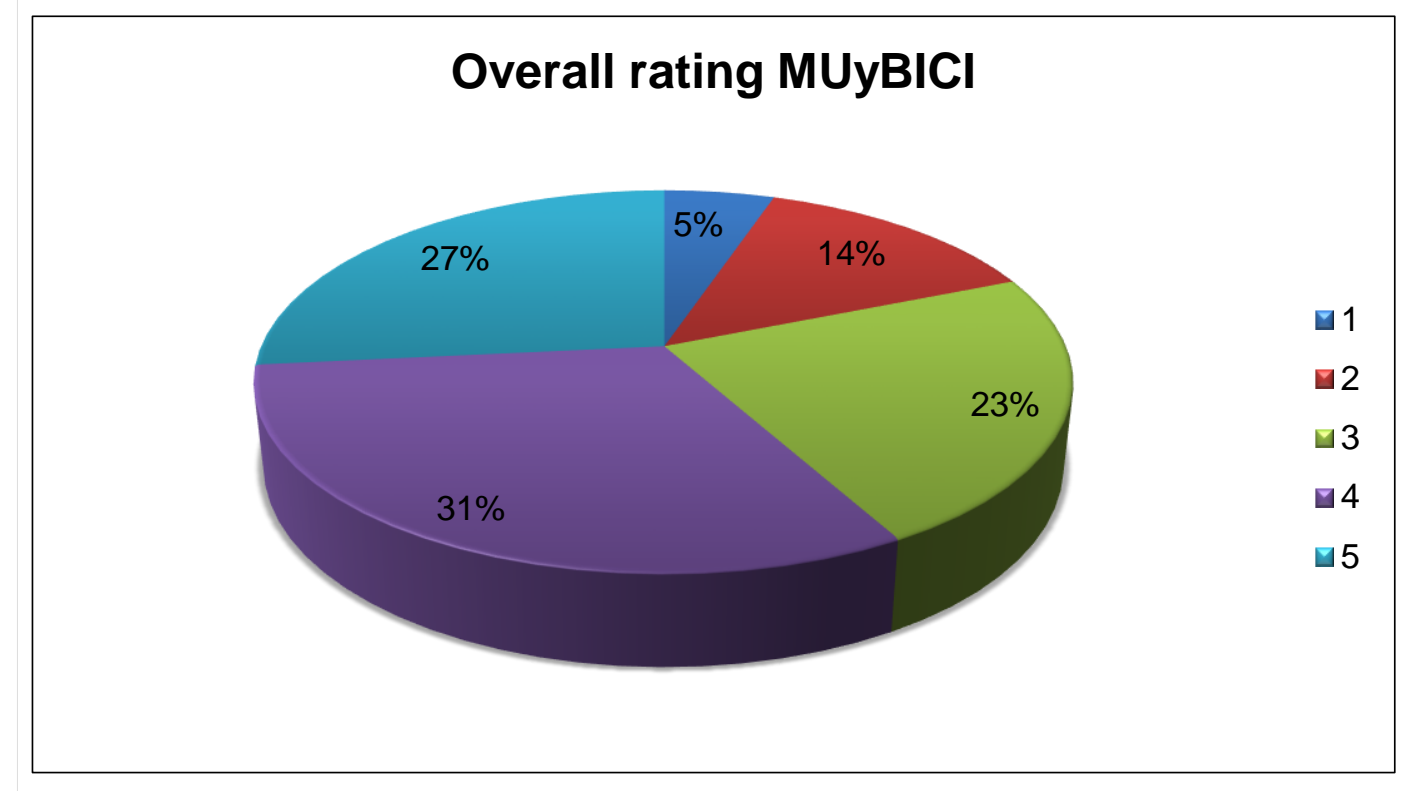

Table 2 - Overall rating of service public bicycle of Murcia

The rating on the location of the thwarts the public bicycle service Murcia, provides 
information on the success of the locations and possible improvements to increase the number of future users who may be available to the public bicycle as a mode of urban transport. Overall, the score on the caucuses is quite good with $76 \%$ of users happy with its placement.

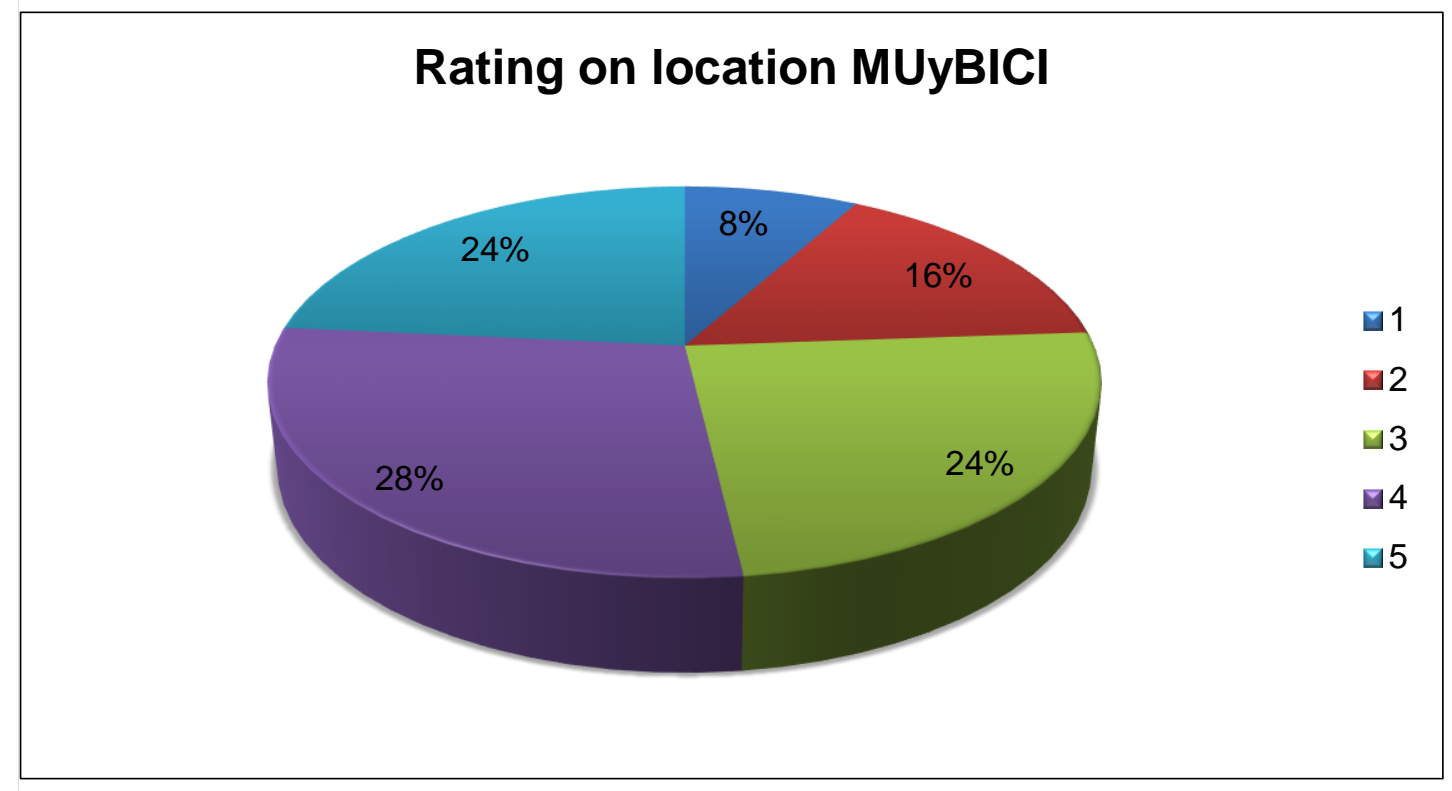

Table 3 - Rating on the location of the public bicycle service of Murcia

\section{CONCLUSIONS.}

Following the methodology for the optimal location of the locations of public bicycle system of Murcia (MUyBICI) has been found good acceptance by the general population of Murcia and, especially, by bicycle users public, with $76 \%$ of citizens who give a good score to the location of the different public bicycle stations scattered throughout the historic center of Murcia.

The implementation of MUyBICI has contributed to the increase in the number of users who choose the bicycle as a regular means of moving in your different trips that occur after a laboral day in the municipality of Murcia. The bicycle's mode of transport has been the largest increase experienced in recent years, which has risen from $1 \%$ in the modal split for 2009 to $5 \%$ today, meaning an increase of 5 times. This is due to the large bet made by the city of Murcia, based on the creation of new bike lanes and the implementation of public bicycle system MUyBICI, with a total of 60 benches and 600 bicycles.

\section{REFERENCES}


Agencia Local de Energía y Medio Ambiente de Murcia (ALEM) (2015). Estudio de movilidad del centro histórico de Murcia para el año 2015. Ayuntamiento de Murcia.

ArcGIS (2012). Tutorial de ArcGIS Network Analyst. ESRI ArcGIS.

Bea Alonso, M., \& Pasqual i Rocabert, J. (2009). Los sistemas de bicicletas públicas urbanas. Universidad Autónoma de Barcelona.

Bosque Sendra, J., \& Moreno Jiménez, A. (2004). Sistemas de información geográfica y localización de instalaciones y equipamientos. Madrid, Ra-Ma.

DeMaio, P. (2009). Bike-sharing: History, impacts, models of provision, and future. Journal of Public Transportation, 12(4), 3.

Hossain, Q. S., Botma, H., Vandebona, U., \& Kiyota, M. (2003). Acceptable access distance to bicycle parking facilities. In Transportation Research Board 2003 Annual Meeting CDROM.

Plan de Movilidad Urbana Sostenible (PMUS) del Municipio de Murcia (2010). Estrategias y Propuestas de Actuación. Ayuntamiento de Murcia.

Plan Director para el uso de la Bicicleta en Murcia (2010). Ayuntamiento de Murcia.

Replogle, M. (1993). IBicycle Access to Public Transportation: Learning from Abroad. 